\title{
Molecular Markers of Gliomas to Predict Treatment and Prognosis: Current State and Future Directions
}

\author{
Catarina Rapôso ${ }^{1}$ • João Luiz Vitorino-Araujo ${ }^{1,2} \bullet$ Natália Barreto $^{1,3}$ \\ ${ }^{1}$ Laboratório de Desenvolvimento de Fármacos - Faculdade de Ciências Farmacêuticas, \\ Universidade Estadual de Campinas (UNICAMP), Brazil; ${ }^{2}$ Disciplina de Neurocirurgia da \\ Faculdade de Ciências Médicas da Santa Casa de São Paulo, Brazil; ${ }^{3}$ Departamento de \\ Biologia Estrutural e Funcional, Instituto de Biologia, UNICAMP, Brazil.
}

Author for correspondence: Catarina Rapôso, Laboratório de Desenvolvimento de Fármacos - Faculdade de Ciências Farmacêuticas (UNICAMP); Cândido Portinari, 200 PO Code 13083-873, Campinas - SP, Brazil. Email: raposo@unicamp.br Doi: https://doi.org/10.36255/exonpublications.gliomas.2021.chapter10

\begin{abstract}
Gliomas used to be classified mainly based on histopathological criteria. In 2016, the Word Health Organization introduced a new classification system incorporating the molecular profile of gliomas. This has prompted research on the utility of molecular signature of gliomas to predict prognosis and response to therapy. While experimental data appear to be promising, the clinical use of molecular markers to predict prognosis and drive individual treatments is still a challenge. This chapter presents an overview of the major genes and markers associated with the characterization and development of gliomas, and the potential of these molecular markers in clinical decision-making. The current challenges and future directions are discussed.
\end{abstract}

Keywords: brain cancer; clinical trials; glioblastoma; molecular markers; therapy

In: Gliomas. Debinski W (Editor). Exon Publications, Brisbane, Australia. ISBN: 978-0-6450017-4-7; Doi: https://doi.org/10.36255/exonpublications.gliomas.2021

Copyright: The Authors.

License: This open access article is licenced under Creative Commons Attribution-NonCommercial 4.0 International (CC BY-NC 4.0) https://creativecommons.org/licenses/by-nc/4.0/ 


\section{INTRODUCTION}

Malignant gliomas can develop anywhere in the central nervous system (CNS), but they mainly occur in the brain, accounting for about $80 \%$ of all primary malignant brain tumors in adults (1). Based on histology, gliomas are traditionally divided into diffuse and non-diffuse gliomas. Diffuse gliomas are characterized by intense infiltrative growth into the surrounding parenchyma of the CNS whereas nondiffuse gliomas are more circumscribed $(2,3)$. Based on the degree of anaplasia, gliomas are graded into non-infiltrating astrocytomas (grade I), diffuse astrocytomas (grade II), anaplastic astrocytomas (grade III) and glioblastoma (grade IV), the most aggressive form (4). Histological diagnosis is based on atypical cell morphology, variation in nuclear size and shape, cell density, mitotic activity, necrosis and vascular properties. Although this classification system based on histology has evolved over the years, there are limitations in diagnostic accuracy, such as being subject to significant interobserver variability, with occasional disagreements between neuropathologists (5). Advances in understanding of molecular pathology of gliomas have led to the incorporation of molecular subtypes of gliomas in the 2016 World Health Organization (WHO) CNS tumor classification $(6,7)$. Current knowledge on the molecular signature of gliomas, how this classification is already driving decisions on treatments and predicting prognosis, and the challenges for using this information in clinical practice are discussed in this chapter.

\section{MOLECULAR CHARACTERIZATION OF GLIOMAS}

During the development of gliomas, genetic and epigenetic changes can culminate in the loss of function of tumor suppressor genes, for example, decreased expression of tumor suppressor protein 53 (TP53), phosphatase and tensin homo$\log$ (PTEN), cyclin-dependent kinase inhibitor 2A (CDKN2A) and retinoblastoma protein $(\mathrm{RB})$; or overexpression of oncogenes, such as rat sarcoma (RAS), phosphatidylinositol-4,5-bisphosphate 3-kinase catalytic subunit alpha (PIK3CA), cyclin dependent kinase 4 (CDK4), murine double minute 2 (MDM2) and epidermal growth factor receptor (EGFR). The loss of TP53 and the consequent activation of the RAS pathway, through inactivation of the neurofibromatosis type 1 (NF1), would be sufficient for the development of diffuse malignant astrocytoma $(8,9)$. This specific change, together with histopathological knowledge, can enable a better diagnostic accuracy and precise prediction of prognosis and responsiveness to antitumor treatments (10).

\section{Diffuse gliomas}

In the WHO 2016 classification, diffuse gliomas (whether astrocytic or oligodendroglial) are grouped not only by behavioral, histological, or growth patterns, but also by punctual genetic changes in the isocitrate dehydrogenase 1 or 2 (IDH1 and IDH2) $(3,11,12)$. Mutations in the 132 or 172 codons of the IDH1 and IDH2 genes, respectively, are present in $80-90 \%$ of low-grade gliomas (WHO grade II/III), and in approximately $5 \%$ of glioblastomas. These mutations result in 
neo-enzymatic activity that culminates in the production of 2-hydroxyglutarate. This causes high histone methylation and hypermethylation of multiple CpG islands; the IDH mutations are possibly one of the first genetic changes that occur during glioma tumorigenesis $(10,12,13)$. However, this alone would not be enough for the development of these types of tumors. IDH-mutant astrocytomas, for example, show additional mutations in the TP53 and alpha thalassemia/mental retardation syndrome $\mathrm{x}$-linked $(A T R X)$ genes, the latter leading to a loss of the nuclear expression of the transcriptional regulator ATRX, which is important for the remodeling of chromatin and regulation of telomere length $(1,10)$. It soon became clear that tumors with the same histological classification, but with a different IDH grading, (IDH-mutant or IDH-wildtype), had different clinical outcomes. In addition, several IDH-wildtype gliomas in adults, classified histologically as diffuse grade II and III, display molecular characteristics and behavior similar to glioblastoma (grade IV) $(11,14,15)$. These observations led to the recognition of the IDH mutation as a suitable biomarker for the categorization of gliomas, introducing the following genetically defined subtypes: anaplastic astrocytoma IDH-mutant, diffuse astrocytoma IDH-mutant, glioblastoma IDH-mutant and oligodendroglioma IDH-mutant. In addition, categories for diffuse IDH-wildtype gliomas have also been created, constituting additional classifications. It is important to highlight that the 2016 WHO classification includes a category entitled not otherwise specified (NOS), for cases in which molecular tests were inconclusive or could not be performed $(11,16)$. The determination of the IDH mutation status is, therefore, essential for the integrated classification of the glioma, which is made possible by immunohistochemistry, using mutant specific antibodies-IDH1R132H being the most common (7). This new characterization of tumors based on the molecular concept, however, is still in its early stages, and more studies that contribute to the identification of the molecular profile of the tumor are needed.

In addition to the presence of the IDH mutation, oligodendroglial tumors demonstrate allelic loss of chromosome $1 p$ and $19 q$ ( $1 p / 19 q$ codelection), which is associated with a favorable prognosis in relation to tumors without this codelection. Many astrocytomas are IDH-mutant and do not have the $1 \mathrm{p} / 19 \mathrm{q}$ codelection $(7,13)$. In this way, the IDH-mutant gliomas can include two main groups: (i) oligodendrogliomas, which, in addition to the IDH mutation, have the $1 \mathrm{p} / 19 \mathrm{q}$ codelection and activating mutation of the telomerase reverse transcriptase (TERT) promoter (mutations in this region increase the expression of TERT, essential for the proliferative character of cancer); and (ii) astrocytomas, characterized by the presence of the IDH mutation and frequent mutation in $\operatorname{ATRX}$ and $\operatorname{TP5} 3(7,11,17)$. The low-grade gliomas without the IDH mutation are called IDH-wildtype and are considered a provisional entity by $2016 \mathrm{WHO}$ classification $(7,15)$. Most lowgrade gliomas have IDH mutations, and $1 \mathrm{p} / 19 \mathrm{q}$ codelection is frequent in oligodendrogliomas; these are prevalent in young adults and their prognosis is favorable, including better responses to radiotherapy and longer survival, compared to diffuse gliomas without these mutations $(9,13)$.

\section{Glioblastomas}

Glioblastomas have also been reclassified into distinct subtypes. About $90 \%$ are now classified as IDH-wildtype; they are located in the supratentorial brain region 
and are characterized by extensive necrosis, TP53 mutations, TERT promoter methylation, EGFR amplification and PTEN mutations. Approximately 10\% of cases are IDH-mutant glioblastoma, considered secondary, which means they may have progressed from a lower grade glioma; they are located in the cerebral frontal lobe and are characterized by limited tumor necrosis, TP53 and ATRX mutations, and TERT promoter mutation (18-20). Overexpression of platelet-derived growth factor receptor alpha (PDGFRA) gene and IDH1 mutation are among the main genetic changes found in low-grade gliomas, as well as in secondary glioblastomas (21). Therefore, based on molecular studies, four glioblastoma subtypes are currently classified: (i) classic (high level of EGFR amplification), (ii) mesenchymal (NF1 mutation or loss), (iii) neural (EGFR overexpression) and (iv) proneural (amplification of PDGFRA) (22).

Another example is the methylation of the O6-methylguanine-DNA methyltransferase (MGMT) promoter (3). The methylation of the MGMT promoter in CpG regions of the DNA correlates with a favorable response to alkylating agents and results in an epigenetic silencing (decreased expression) of the MGMT protein, reducing the repair activity by this protein. This methylation is observed in approximately $40 \%$ of all glioblastomas. Higher promoter methylation levels predict longer survival for patients with glioblastoma (22 months, versus 13 for patients with unmethylated tumors) $(3,23)$.

\section{MOLECULAR PROFILE GUIDING CLINICAL PRACTICE}

According to the European Organization for Research and Treatment of Cancer (EORTC) 22844 study, the factors that confer poor prognosis for low-grade gliomas are: (i) age equal to or older than 40 years; (ii) histology compatible with astrocytoma; (iii) tumor diameter equal to or greater than $6 \mathrm{~cm}$; (iv) tumor that exceeds the midline; and (v) presence of neurological deficits prior to surgery (24). In this context, patients who have any of the two of the factors are considered low-risk, and the mean overall survival is 7.8 years; those who have three or more factors are considered high-risk and the mean overall survival is 3.7 years (25). The presence of MGMT methylation, IDH mutation, or both, associated with 1p/ 19 q codelection offer a better prognosis with a greater overall survival. However, MGMT methylation, IDH mutation, and TP53 immunopositivity were associated with a higher rate of malignant transformation of tumors (26).

The extent of surgical resection is a predictor of overall survival, epileptic seizures and tumor recurrence $(27,28)$. Complete resection of the lesion provides a better prognosis. Some studies suggest that a supratotal resection reduces the incidence of malignant transformation, decreases tumor recurrence, and promotes greater survival in low-grade gliomas $(29,30)$. The correlation between the molecular type and the degree of resection suggests differences in prognosis between astrocytomas (mean survival $=10.9$ years) and oligodendroglioma (mean survival $=17.1$ years). In grade II astrocytomas (IDH-mutant), a tumor residue with a volume of 0.1 to $5.0 \mathrm{~cm}^{3}$ is associated with a significant reduction in survival compared to total tumor resection whereas in grade II oligodendrogliomas (IDH-mutant, $1 \mathrm{p} / 19 \mathrm{q}$ codeletion), there is no such difference. This is also the case with grade III anaplasic astrocytomas (IDH-mutant) and anaplastic 
oligodendrogliomas (IDH-mutant and $1 \mathrm{p} / 19 \mathrm{q}$ codeletion) (31). This reinforces the importance of surgical radicality, especially in the case of tumors of astrocytic lineage, which by nature have a worse prognosis than tumors of oligodendroglial lineage. In addition, these studies demonstrate the clinical relevance of the molecular signature of the tumor to predict the prognosis after surgical resection. Despite these advances, the use of this knowledge to assist in clinical management and the development of effective therapies has not yet been consolidated and systematized. The standard treatment, in most countries, still consists of maximum safe resection associated with radiotherapy and chemotherapy (Figure 1) $(31,32$ ).

For glioblastoma, the factors for good prognosis are age less than 45 years, Karnofsky Performance Scale (KPS) greater than $80 \%$, and degree of resection greater than 78\% (33-35). Liang et al. (32) showed that low KPS $(<85 \%)$ is an independent risk factor for death in the first year of treatment of patients, regardless of histological grade. The degree of surgical resection and adjuvant radio and chemotherapy (temozolomide - TMZ) is associated with increased overall survival and delayed tumor progression, despite the high recurrence of gliomas (36). At molecular level, MGMT promoter methylation, $1 \mathrm{p} / 19 \mathrm{q}$ codeletion and IDH1 mutation are markers and predictors of a favorable prognosis. Tumor-treating fields in combination with TMZ increase overall survival and disease-free survival compared to TMZ alone (37). However, tumor-treating fields is not a target-driven

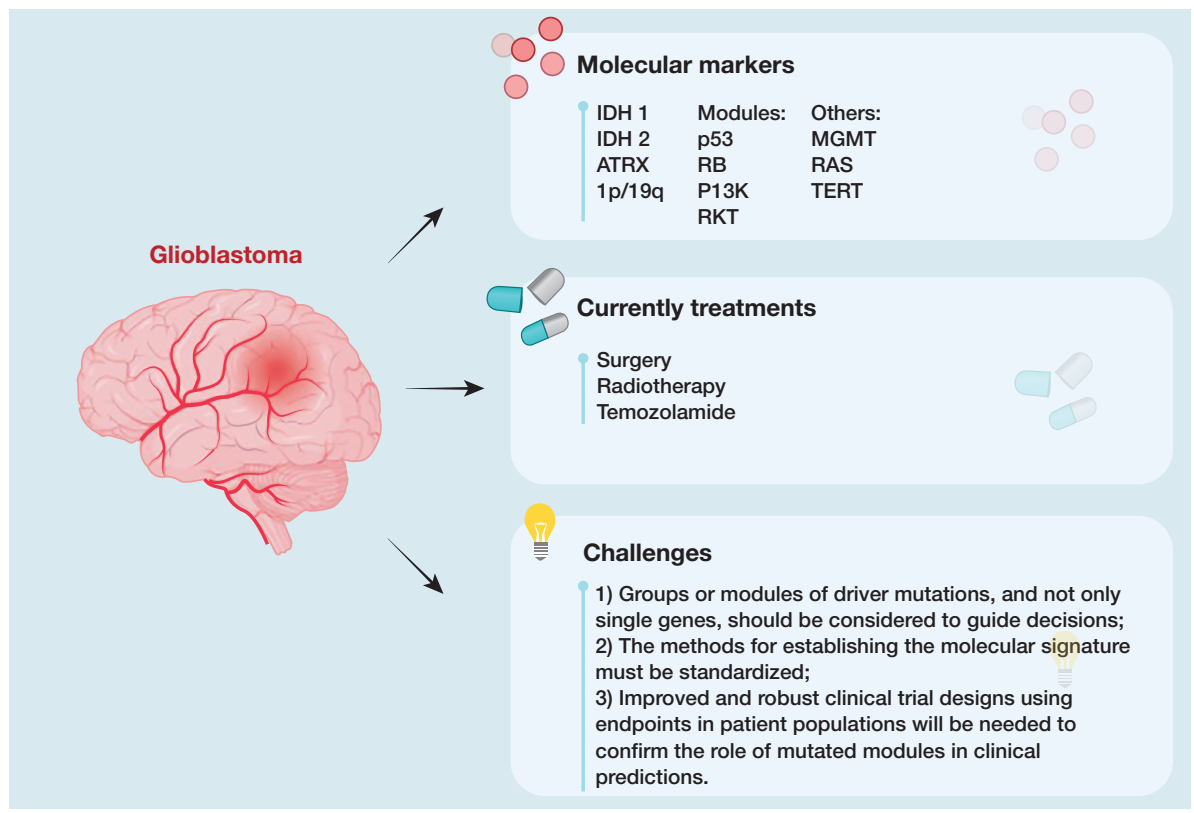

Figure 1. Molecular markers and current challenges. The schematic representation includes the markers and modules listed in the chapter, as well as the main therapies for the treatment of glioma and the challenges to use tumor molecular signature to guide treatments and predict prognosis. 
therapy and there is no study correlating the clinical response with the molecular profile of the tumor.

In the EORTC phase III study, 437 patients with recurrent glioblastoma after radio and $\mathrm{TMZ}$ therapy were randomized to receive lomustine or lomustine plus bevacizumab (38). IDH mutations and MGMT promoter methylation were monitored. The combination therapy demonstrated a marginal increase in progressionfree survival (1.5 months for lomustine and 4.1 months for the combination) without any improvement in overall survival. The BRAF V600E gene mutation has been identified in approximately $50 \%$ of glioblastomas (39). In a phase II study of 24 patients with the mutation, vemurafenib, an inhibitor of the BRAF kinase domain, demonstrated a lasting response and stable disease for 12.9 months (40).

While the limited prognostic value of IDH1 mutations have been demonstrated, little is known about other genes often mutated in gliomas, including TP53, PTEN, CDKN2A, RB1, EGFR, NF1, PIK3CA, phosphoinositide3-kinase regulatory subunit 1 (PIK3R1) and others. Although many clinical trials are underway (Table 1), to the best of our knowledge, no study has been published so far in which the treatment decisions were made based on the molecular classification of the glioma. MGMT methylation status remains the most reliable tumor biomarker, as it can be used to predict the tumor's response to the therapy with TMZ (41). Also, the $1 \mathrm{p} / 19 \mathrm{q}$ co-deletion is a consistent marker, and has been used as a molecular signature of oligodendroglial tumors, predicting the response to vincristine chemotherapy of anaplastic gliomas (42). However, before adapting the molecular classification in clinical practice, further studies are needed.

\section{FUTURE DIRECTIONS}

Based on the current knowledge, it is possible to define three main challenges that need to be considered going forward to be successful in predicting prognosis and treatment: (i) identifying functional modules or groups of driver mutations, rather single genes; (ii) standardization of methods for establishing molecular signature; and (iii) molecular markers-based clinical trial designs.

\section{Functional modules}

The first challenge is identifying functional modules, a set of altered genes with functional relevance in gliomas. Cerami et al. (43) observed that genetic alterations in glioblastoma tend to occur within three main specific functional modules: p53, RB and PI3K. Each module contains groups of mutations. For example, the gene alterations identified in module p53 are TP53, MDM2, and mouse double minute 4 - MDM4; the RB module are RB1, CDK4, and CDKN2A; and the PI3K module are PIK3CA, PIK3R1, PTEN, and insulin receptor substrate 1 (IRS1). In addition to these three modules, the receptor tyrosine kinases (RTK) module has been described. It contains amplification or mutation of the EGFR gene, BRAF mutation, neurotrophic tyrosine receptor kinase (NTRK) or fibroblast growth factor receptor (FGFR) gene fusions, and amplification or fusion of the MET gene (44). 


\section{TABLE 1 Clinical trials correlating treatment and molecular profile of gliomas}

\begin{tabular}{|c|c|c|}
\hline Name & Description & Observations \\
\hline $\begin{array}{l}\text { Molecular profiling in guiding } \\
\text { individualized treatment plan in } \\
\text { adults with recurrent/progressive } \\
\text { glioblastoma (TGEN) }\end{array}$ & $\begin{array}{l}\text { Tumor tissue from patients with } \\
\text { glioblastoma undergoing surgery } \\
\text { is collected for analysis of the } \\
\text { molecular profile together with } \\
\text { DNA from blood samples. Drugs } \\
\text { could be suggested, and the } \\
\text { molecular data will be correlated } \\
\text { with tumor progression and } \\
\text { patient survival in treated and } \\
\text { untreated groups. }\end{array}$ & $\begin{array}{l}\text { Status: Completed } \\
\text { Country: USA } \\
\text { Last update: posted: } \\
\text { Jul 28, } 2020 \\
\text { ClinicalTrials.gov } \\
\text { identifier: } \\
\text { NCT02060890 }\end{array}$ \\
\hline $\begin{array}{l}\text { Chemotherapy and radiation therapy } \\
\text { for the treatment of IDH wildtype } \\
\text { gliomas or non-histological } \\
\text { molecular) glioblastomas }\end{array}$ & $\begin{array}{l}\text { Phase II study that evaluates the } \\
\text { relationship between the use of } \\
\text { temozolomide and radiotherapy } \\
\text { in the treatment of patients with } \\
\text { low-grade gliomas, IDH-wild type } \\
\text { glioblastoma or non-histological } \\
\text { molecular glioblastomas. }\end{array}$ & $\begin{array}{l}\text { Status: Recruiting } \\
\text { Country: USA } \\
\text { Last update: posted: } \\
\quad \text { Nov } 10,2020 \\
\text { ClinicalTrials.gov } \\
\text { identifier: } \\
\text { NCT04623931 }\end{array}$ \\
\hline $\begin{array}{l}\text { Feasibility of individualized therapy } \\
\text { for recurrent GBM }\end{array}$ & $\begin{array}{l}\text { A pilot study that evaluates the } \\
\text { feasibility of implementation for } \\
\text { individualized treatment based } \\
\text { on a report of the genetic profile } \\
\text { of patients with recurrent surgical } \\
\text { glioblastoma. }\end{array}$ & $\begin{array}{l}\text { Status: Active, not } \\
\text { recruiting } \\
\text { Country: USA } \\
\text { Last update: posted: } \\
\text { Apr 28, } 2020 \\
\text { ClinicalTrials.gov } \\
\text { identifier: } \\
\text { NCT03681028 }\end{array}$ \\
\hline $\begin{array}{l}\text { Clinical benefit of using molecular } \\
\text { profiling to determine an } \\
\text { individualized treatment plan for } \\
\text { patients with high grade glioma } \\
\text { (PNOC008) }\end{array}$ & $\begin{array}{l}\text { The study evaluates a new treatment } \\
\text { approach based on patient's tumor } \\
\text { gene expression in children with } \\
\text { high-grade gliomas. }\end{array}$ & $\begin{array}{l}\text { Status: Recruiting } \\
\text { Country: USA } \\
\text { Last update: posted: } \\
\text { Dec 04, } 2020 \\
\text { ClinicalTrials.gov } \\
\text { identifier: } \\
\text { NCT03739372 }\end{array}$ \\
\hline $\begin{array}{l}\text { Treatment response and prognosis } \\
\text { in glioma patients: Q Cell and its } \\
\text { biological characteristics }\end{array}$ & $\begin{array}{l}\text { The study analyzes the molecular } \\
\text { markers of patients with } \\
\text { glioblastoma that will be evaluated } \\
\text { qualitatively and quantitatively, } \\
\text { comparing their relationship } \\
\text { with survival/survival free of } \\
\text { progression and response to } \\
\text { treatment. }\end{array}$ & $\begin{array}{l}\text { Status: Unknown } \\
\text { Country: China } \\
\text { Last update: posted: } \\
\text { Jan } 28,2014 \\
\text { ClinicalTrials.gov } \\
\text { identifier: } \\
\text { NCT02047058 }\end{array}$ \\
\hline
\end{tabular}




\section{TABLE 1 Clinical trials correlating treatment and molecular profile of gliomas (Continued)}

\begin{tabular}{|c|c|c|}
\hline Name & Description & Observations \\
\hline $\begin{array}{l}\text { Pilot study of Abemaciclib with } \\
\text { Bevacizumab in recurrent } \\
\text { glioblastoma patients with } \\
\text { loss of CDKN2A/B or gain or } \\
\text { amplification of CDK/6 }\end{array}$ & $\begin{array}{l}\text { The study describes the effects of } \\
\text { Abemaciclib administered with } \\
\text { Bevacizumab in patients with } \\
\text { recurrent glioblastoma with } \\
\text { specific molecular changes. }\end{array}$ & $\begin{array}{l}\text { Status: Recruiting } \\
\text { Country: USA } \\
\text { Last update: posted: } \\
\text { Jan 07, 2020 } \\
\text { ClinicalTrials.gov } \\
\text { identifier: } \\
\text { NCT04074785 }\end{array}$ \\
\hline $\begin{array}{l}\text { Imetelstat sodium in treating } \\
\text { younger patients with recurrent or } \\
\text { refractory brain tumors }\end{array}$ & $\begin{array}{l}\text { This phase II molecular biology study } \\
\text { looks at how sodium imetelstat } \\
\text { works in treating younger patients } \\
\text { with refractory or recurrent brain } \\
\text { tumors. }\end{array}$ & $\begin{array}{l}\text { Status: Terminated } \\
\text { Country: USA } \\
\text { Last update: posted: } \\
\text { Jul 20, } 2018 \\
\text { ClinicalTrials.gov } \\
\text { identifier: } \\
\text { NCT01836549 }\end{array}$ \\
\hline $\begin{array}{l}\text { NCT Neuro Master Match - } \mathrm{N}^{2} \mathrm{M}^{2} \\
(\mathrm{NOA}-20)\left(\mathrm{N}^{2} \mathrm{M}^{2}\right)\end{array}$ & $\begin{array}{l}\text { The study assesses the improvement } \\
\text { of overall survival of patients with } \\
\text { glioblastoma with an unmethylated } \\
\text { MGMT promoter based on } \\
\text { molecular characterization and use } \\
\text { of targeted compounds in a trial } \\
\text { design. }\end{array}$ & $\begin{array}{l}\text { Status: Recruiting } \\
\text { Country: Germany } \\
\text { Last update: posted: } \\
\text { Feb 27, } 2020 \\
\text { ClinicalTrials.gov } \\
\text { identifier: } \\
\text { NCT03158389 }\end{array}$ \\
\hline $\begin{array}{l}\text { Lapatinib in treating young patients } \\
\text { with recurrent or refractory central } \\
\text { nervous system tumors }\end{array}$ & $\begin{array}{l}\text { This phase I/II trial studies lapatinib } \\
\text { to see how well it works in treating } \\
\text { young patients with recurrent or } \\
\text { refractory central nervous system } \\
\text { tumors also correlating with } \\
\text { molecular aspects. }\end{array}$ & $\begin{array}{l}\text { Status: Completed } \\
\text { Country: USA } \\
\text { Last update: posted: } \\
\text { May 23, 2014 } \\
\text { ClinicalTrials.gov } \\
\text { identifier: } \\
\text { NCT00095940 }\end{array}$ \\
\hline $\begin{array}{l}\text { Improving the selection of patients } \\
\text { with glioblastoma multiforme for } \\
\text { treatment with epidermal growth } \\
\text { factor receptor inhibitor therapies }\end{array}$ & $\begin{array}{l}\text { The study assesses biomarkers that } \\
\text { can improve patient selection for } \\
\text { therapies with epidermal growth } \\
\text { factor receptor inhibitors. }\end{array}$ & $\begin{array}{l}\text { Status: Completed } \\
\text { Country: USA } \\
\text { Last update: posted: } \\
\text { Jan } 24,2018 \\
\text { ClinicalTrials.gov } \\
\text { identifier: } \\
\text { NCT00897663 }\end{array}$ \\
\hline
\end{tabular}

Zhang et al. (45) searched for mutated core modules in glioblastoma and ovarian carcinoma datasets and identified five and two mutated modules, respectively. For glioblastoma, cyclin-dependent kinase inhibitor 2B (CDKN2B) and CDK4 for the RB module, and EGFR and NF1 for the RTK module were detected.

The International Cancer Genome and The Atlas of the Cancer Genome (TCGA; in which glioblastoma was the first tumor examined) are initiatives to understand the genetics of tumors, helping in the generation of new therapies 
and better diagnostic methods. With these platforms, researchers from several countries use samples of gliomas from multiple centers to carry out comprehensive molecular characterization $(9,17,46)$. Using the TGGA database, Gu et al. (47) identified multiple co-occurring alterations among the three modules mentioned above (TP53, RB and RTK). For example, simultaneous co-alterations in RTK and TP53 modules were present in 31 glioblastoma patients. Forty-one glioblastoma samples carried alterations in the RTK-related module, which consisted of EGFR, PIK3CA, phosphatidylinositol-4-phosphate 3-kinase catalytic subunit type 2 beta (PIK3C2B), ATP synthase F1 subunit beta (ATP5B) and mitogen-activated protein kinase 14 (MAPK14). Thirty-five samples were detected with alterations in the p53-related module, including CDKN2A, MDM4, E1A binding protein p300 (EP300), CD4, major histocompatibility complex class II (MHC II), DR alpha (HLA-DRA), diacylglycerol kinase gamma (DGKG) and heat shock protein 90 alpha family class A member 1 (HSP90AA1). Alterations within the $R B$ module included amplifications of cyclin-dependent kinase inhibitor $1 \mathrm{~B}$ (CDKN1B) and mutations of RB1, IQ motif containing GTPase activating protein 1 (IQGAP1), WEEl G2 checkpoint kinase (WEE1) and ephrin type-A receptor 7 (EPHA7B).

Taken together, it is possible to establish four main modules for the molecular signature of gliomas: (i) p53 (including CDKN2A/2B, TP53, MDM2, MDM4, EP300, CD4, HLA-DRA, DGKG and HSP90AA); (ii) RB (including CDKN1B, CDKN2B, RB1, IQGAP1, WEE1, EPHA7By, CDK4 and CDKN2A); (iii) PI3K (including PIK3CA, PIK3R1, PTEN), and (iv) IRS1 and RTK (including EGFR, PIK3CA, PIK3C2B, ATP5B, MAPK14, BRAF, MET, NTRK, FGFR and NF1). Other genes involved in each module, as well as new modules, can be further identified, since this field is still emerging.

Tang et al. (42) identified a module with four genes associated with survival: c-type lectin domain family 5 member A (CLEC5A), fibromodulin (FMOD), FKBP prolyl isomerase 9 (FKBP9) and galectin 8 (LGALS8) (48). CLEC5A/ MDL-1 is a member of the myeloid C-type lectin family expressed in macrophages and neutrophils; FMOD, a glioblastoma-upregulated gene, promotes glioma cell migration through its ability to generate the formation of filamentous actin stress fibers; FKBP9 is a peptidyl-prolyl isomerase and it has been implicated in neurodegeneration, mainly through accelerating fibrillization; and LGALS8 plays functional roles in promoting glioblastoma cell proliferation and clonal sphere formation.

Based on RNA-Seq from TGGA database, Xu et al. identified a module with four genes related to prognosis: oncostatin m receptor (OSMR), SRY-box transcription factor 21 (SOX21), mediator complex subunit 10 (MED10) and protein tyrosine phosphatase receptor type N (PTPRN) (49). OSMR encodes a member of the type I cytokine receptor family; SOX21 functions as a tumor suppressor during glioma genesis; MED10 is a component of the coactivator for DNA-binding factors that activate transcription via RNA polymerase II; and PTPRN is a member of the protein tyrosine phosphatase family and may be involved in cancer initiation and progression. Although the specific mechanisms of glioma progression remain to be fully elucidated, these modules can be of assistance in studying the progression and prognosis of gliomas and help develop novel therapeutics and guide clinical practice. 


\section{Standardization of methods}

The second challenge is to have standardized methods for determining the molecular signature of tumors. When choosing techniques, it is important to consider complexity, reproducibility, and costs. In addition, sample collections must be standardized. To evaluate the main aberrations, such as $1 \mathrm{p} / 19 \mathrm{q}$ co-deletion, IDH and histone $\mathrm{H} 3$ mutations, direct sequencing, multiplex ligation-dependent probe amplification and/or fluorescence in situ hybridization (FISH) are used. However, these methods are complex and costly. Real-time quantitative PCR (qPCR) and immunohistochemistry have also been used and are considered simple and accurate techniques in the daily diagnosis, readily available for a small scientific facility (50). However, new diagnostic resources that are simpler, faster and easier to standardize, with established sensitivity, specificity and predictive values, are necessary for molecular information in the clinic.

Research groups around the world are trying to improve methodology and establish protocols. Shi et al. collected tumor tissues using image-guidance by magnetic resonance (MR) from 26 cases of glioblastoma, showing that this approach increased the content and purity of the samples compared with manual extraction (51). An ongoing study (ClinicalTrials.gov Identifier: NCT04539431) is validating a new platform for molecular characterization of patients affected by glioma. This includes a series of faster and less expensive qPCR methodologies compared to the standard analyzes (DS, MS-PCR).

Another important point to consider is tumor samples bias, which can occur due to somatic events in the primary tumor, between the primary and metastatic sites, and among metastatic sites, generating intra-tumor molecular heterogeneity (52). Taking samples from different parts of the tumors and metastases can help minimize this problem. In addition, methods for biobanking of gliomas derived from patients can also be a very rich tool for future analysis. Jacob et al. developed methods for generating glioblastoma organoids with high reliability, exhibiting rapid and aggressive infiltration when transplanted into adult rodent brains (53). They demonstrated the usefulness of glioblastoma organoids for testing personalized therapies, correlating mutational glioblastoma profiles with responses to specific drugs. The organoids maintained many key characteristics of original glioblastoma. In their work, 96.4\% of IDH1-wildtype tumors resulted in organoids, but IDH1-mutant and recurrent tumors showed reduced success rates.

Our research group is conducting a translational study at the "Hospital Central da Irmandade da Santa Casa de Misericordia de São Paulo", São Paulo, Brazil, characterizing the molecular signature of gliomas. The objectives are to improve diagnostic methods, prognostic predictions using simple and low-cost techniques, and correlate molecular profile with response to standard and new treatments. The study is approved by the Brazilian Research Ethics Committee (Comitê de Ética em Pesquisa - CEP, \#15215219.5.0000.5404). Briefly, tumor samples from patients are processed for molecular analysis. The biomarkers evaluated include those described in the WHO 2016 glioma classification, as well as other related markers (including markers from the major known modules), as detailed in Figure 2. The establishment of each tumor lineage in culture, as well as tissue samples, will be used later for the creation of 
a biobank. The results of the analysis of the molecular profile will be made available to the medical team and will be of great importance for directing the most appropriate and specific adjuvant treatment. The established lineages of tumors can be used later to confirm tumor profile and response to other treatments. Epidemiological statistics will also be generated to contribute to the mapping of cases of brain cancer in the Brazil Unified Health System (Sistema Único de Saúde - SUS).

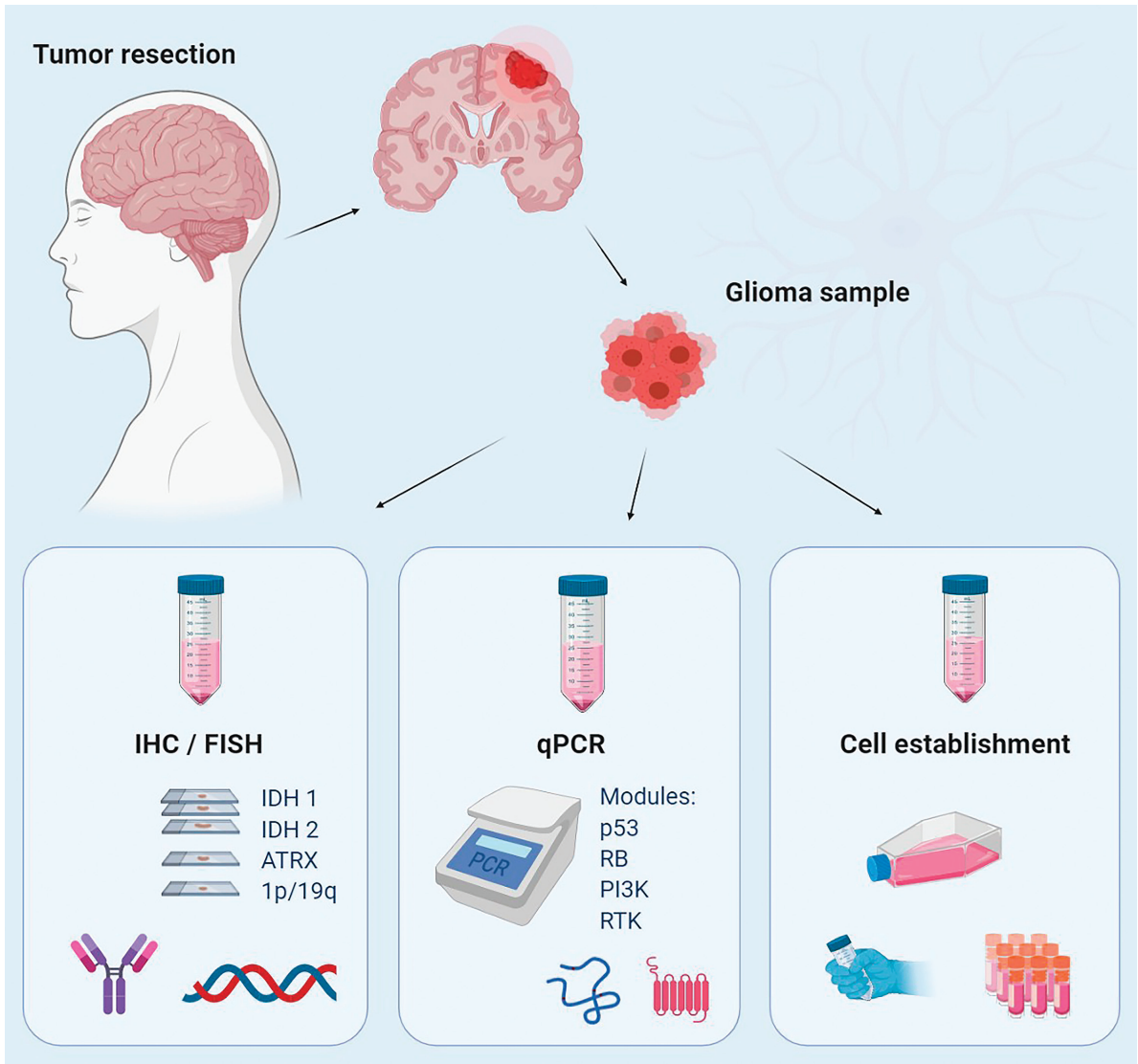

Figure 2. Schematic representation of the protocol for collecting and analyzing the molecular profile of glioma samples. After collection and adequate conditioning of the tumor sample, IHC and FISH techniques will be performed to determine the expression of the markers: IDH 1 and 2; ATRX and 1p/19q codeletion, respectively. qPCR analyzes will be carried out to evaluate the molecular markers modules: p53 (TP53), RB (CDKN2A), PI3K (PIK3CA), and RTK (EGFR and NF1). Other related molecular markers also will be evaluated such as MGMT and PDGFRA, AKT, mTOR, Rhoa, and ROCK (related to tumor development and also with cell migration and proliferation pathways, respectively). The establishment of the culture sample will analyze other parameters and also will be used, together with tissue samples, for the creation of a biobank. 


\section{Clinical trials}

The third challenge is designing clinical trials based on the molecular signature of tumors. Although several studies are testing new drugs or combination therapies, only a few clinical trials are focused on establishing the effectiveness of individual treatments driven by the molecular profile of the tumor. Some studies in this field, recorded at ClinicalTrials.gov, are listed in Table 1. Most take into account the mutation in IDH, while p53, RB, PI3K and RTK modules have been neglected. Current studies mainly seek to determine whether a molecular signature respond to the chosen treatment. There are no published or current studies to date using the molecular signature of the tumor as a basis to choose treatment. This indicates that it will take a long time to have solid data in this area. Another problem is the inconsistency between studies, as they often do not confirm the findings of each other. These inconsistencies are caused mainly by the lack of standardized methods for assessing the molecular signature of tumors, the biological variability of tumors, and paucity of knowledge about the gene modules and interactions between the modules. Further studies are needed to provide simplified, standardized and clinically applicable protocols for the characterization of individual tumors, which should assist in defining the prognosis of the disease and guide the choice of treatment.

\section{CONCLUSION}

While there has been a rapid advance in our understanding of the molecular profile of gliomas, there are several challenges that impair the translation of this knowledge into clinical practice. Several markers and signaling pathways are involved concomitantly in tumor development and progression and these need to be fully elucidated for more effective therapeutic strategies. The identification of functional modules relevant to glioblastoma are promising. There is a need to standardize the methods for collection, processing, preservation and analysis of tumor samples. While MR-guided sampling improves tumor content and purity, the practicality of this method in day-to-day clinical practice still needs to be established. Results of ongoing clinical trials such as NCT04539431 and our own study should shed some light in this area in the future. It is heartening to see many clinical trials incorporating molecular markers (Table 1) in study design. The results of these studies have the potential to help develop personalized medicine strategies based on molecular profile of gliomas.

Acknowledgment: This work was supported by the following Brazilian foundations: Fundação de Amparo à Pesquisa do Estado de São Paulo (the São Paulo Research Foundation - FAPESP - Grant \#15/04194-0) and Conselho Nacional de Desenvolvimento Científco e Tecnológico (the Brazilian National Council for Scientifc and Technological Development - CNPq - Grant \#431465/2016-9). Natália Barreto dos Santos is fellow of FAPESP (\#17/16196-2; \#19/10003-3).

Conflict of interest: The authors declare no potential conflict of interest with respect to research, authorship and/or publication of this chapter. 
Copyright and permission statement: The authors confirm that the materials included in this chapter do not violate copyright laws. Where relevant, appropriate permissions have been obtained from the original copyright holder(s), and all original sources have been appropriately acknowledged or referenced.

\section{REFERENCES}

1. Weller M, Wick W, Aldape K, Brada M, Berger M, Pfister SM, et al. Glioma. Nat Rev Dis Prim. $2015 ; 1$. https://doi.org/10.1038/nrdp.2015.17

2. Perry A, Wesseling P. Histologic classification of gliomas. Handb Clin Neurol. 2016;134:71-95. https://doi.org/10.1016/B978-0-12-802997-8.00005-0

3. Chen R, Smith-Cohn M, Cohen AL, Colman H. Glioma Subclassifications and Their Clinical Significance. Neurotherapeutics. 2017;14(2):284-97. https://doi.org/10.1007/s13311-017-0519-x

4. Reifenberger G, Wirsching HG, Knobbe-Thomsen CB, Weller M. Advances in the molecular genetics of gliomas-implications for classification and therapy. Nat Rev Clin Oncol. 2017;14(7):434-52. https://doi.org/10.1038/nrclinonc.2016.204

5. Brandner S, Jaunmuktane Z. Neurological update: gliomas and other primary brain tumours in adults. J Neurol. 2018;265(3):717-27. https://doi.org/10.1007/s00415-017-8652-3

6. Sharma S, Kelly TK, Jones PA. Epigenetics in cancer. Carcinogenesis. 2009;31(1):27-36. https://doi. org/10.1093/carcin/bgp220

7. Gusyatiner O, Hegi ME. Glioma epigenetics: From subclassification to novel treatment options. Seminars in Cancer Biology. 2018; 51:50-8. https://doi.org/10.1016/j.semcancer.2017.11.010

8. Miyai M, Tomita H, Soeda A, Yano H, Iwama T, Hara A. Current trends in mouse models of glioblastoma. J Neurooncol. 2017;135(3):423-32. https://doi.org/10.1007/s11060-017-2626-2

9. The Cancer Genome Atlas Research Network. Comprehensive, integrative genomic analysis of diffuse lower-grade gliomas. N Engl J Med. 2015;372(26):2481-98. https://doi.org/10.1056/ NEJMoal402121

10. Veliz I, Loo Y, Castillo O, Karachaliou N, Nigro O, Rosell R. Advances and challenges in the molecular biology and treatment of glioblastoma-is there any hope for the future? Ann Transl Med. 2015;3(1):7.

11. Wesseling P, Capper D. WHO 2016 Classification of gliomas. Neuropathol Appl Neurobiol. 2018;44(2):139-50. https://doi.org/10.1111/nan.12432

12. Parsons DW, Jones S, Zhang X, Lin JCH, Leary RJ, Angenendt P, et al. An integrated genomic analysis of human glioblastoma multiforme. Science. 2008;321(5897):1807-12. https://doi.org/10.1126/ science. 1164382

13. Miller JJ, Shih HA, Andronesi OC, Cahill DP. Isocitrate dehydrogenase-mutant glioma: Evolving clinical and therapeutic implications. Cancer. 2017;123(23):4535-46. https://doi.org/10.1002/ cncr.31039

14. Alphandéry E. Glioblastoma treatments: an account of recent industrial developments. Front Pharmacol. 2018 Sep;9:1-31. https://doi.org/10.3389/fphar.2018.00879

15. Reuss DE, Kratz A, Sahm F, Capper D, Schrimpf D, Koelsche C, et al. Adult IDH wild type astrocytomas biologically and clinically resolve into other tumor entities. Acta Neuropathol. 2015;130(3): 407-17. https://doi.org/10.1007/s00401-015-1454-8

16. Diamandis P, Aldape K. World Health Organization 2016 Classification of Central Nervous System Tumors. Neurol Clin. 2018;36(3):439-47. https://doi.org/10.1016/j.ncl.2018.04.003

17. Chen Y, Chou WC, Ding YM, Wu YC. Caffeine inhibits migration in glioma cells through the ROCKFAK pathway. Cell Physiol Biochem. 2014;33(6):1888-98. https://doi.org/10.1159/000362966

18. Ferris SP, Hofmann JW, Solomon DA, Perry A. Characterization of gliomas: from morphology to molecules. Virchows Arch. 2017;471(2):257-69. https://doi.org/10.1007/s00428-017-2181-4

19. Cambruzzi E. The role of IDH1/2 mutations in the pathogenesis of secondary glioblastomas. J Bras Patol e Med Lab. 2017;53(5):338-44. https://doi.org/10.5935/1676-2444.20170055 
20. Ghosh D, Nandi S, Bhattacharjee S. Combination therapy to checkmate Glioblastoma: clinical challenges and advances. Clin Transl Med. 2018;7(1):33. https://doi.org/10.1186/s40169-018-0211-8

21. Liu KW, Hu B, Cheng SY. Platelet-derived growth factor receptor alpha in Glioma: A bed seed. Chinese Journal of Cancer. 2011; 30(9):590-602. https://doi.org/10.5732/cjc.011.10236

22. Verhaak RGW, Hoadley KA, Purdom E, Wang V, Qi Y, Wilkerson MD, et al. Integrated genomic analysis identifies clinically relevant subtypes of glioblastoma cCharacterized by abnormalities in PDGFRA, IDH1, EGFR, and NF1. Cancer Cell. 2010;17(1):98-110. https://doi.org/10.1016/j.ccr.2009.12.020

23. Esteller M, Garcia-Foncillas J, Andion E, Goodman SN, Hidalgo OF, Vanaclocha V, et al. Inactivation of the DNA-repair gene MGMT and the clinical response of gliomas to alkylating agents. N Engl J Med. 2000 Nov;343. https://doi.org/10.1056/NEJM200011093431901

24. Karim AB, Maat B, Hatlevoll R, Menten J, Rutten EH, Thomas DG, et al. A randomized trial on dose-response in radiation therapy of low-grade cerebral glioma: European Organization for Research and Treatment of Cancer (EORTC) Study 22844. Int J Radiat Oncol Biol Phys. 1996;36(3):549-56. https://doi.org/10.1016/S0360-3016(96)00352-5

25. Pignatti F, van den Bent M, Curran D, Debruyne C, Sylvester R, Therasse P, et al. European Organization for Research and Treatment of Cancer Brain Tumor Cooperative Group. Prognostic factors for survival in adult patients with cerebral low-grade glioma. J Clin Oncol. 2002;20(8):2076-84. https://doi. org/10.1200/JCO.2002.08.121

26. Leu S, von Felten S, Frank S, Vassela E, Vajtai I, Taylor E, et al. IDH/MGMT driven molecular classification of low-grade glioma is a strong predictor for long-term survival. Neuro Oncol. 2013;15940: 469-79. https://doi.org/10.1093/neuonc/nos317

27. Sanai N, Berger MS. Surgical oncology for gliomas: the state of the art. Nat Rev Clin Oncol. 2018;15:112-25. https://doi.org/10.1038/nrclinonc.2017.171

28. Xia L, Fang C, Chen G, Sun C. Relationship between the extent of resection and the survival of patients with low grade gliomas: a systematic review and meta-analysis. BMC Cancer. 2018;18(1):48. https://doi.org/10.1186/s12885-017-3909-x

29. Yordanova YN, Moritz-Gasser S, Duffau H. Awake surgery for WHO grade II gliomas within "noneloquent" areas in the left dominant hemisphere: toward a "supratotal' resection. J Neurosurg. 2011;115(2):232-9. https://doi.org/10.3171/2011.3.JNS101333

30. Duffau H. Long-term outcomes after suprtaotal resection of diffuse low-grade gliomas: a consecutive series with 11 year follow-up. Acta Neurochir (Wien). 2016;158(1):51-8. https://doi.org/10.1007/ s00701-015-2621-3

31. Clark VE, Cahill DP. Extent of resection versus molecular classification. What matters when?. Neurosurg Clin N Am. 2019;95-101. https://doi.org/10.1016/j.nec.2018.08.006

32. Liang J, Xiaomin LV, Changyu LU, et al. Prognostic factors od patients with gliomas - na analysis on 335 patients with Glioblastoma and other forms of Gliomas. BMC Cancer. 2020;20:35. https://doi. org/10.1186/s12885-019-6511-6

33. Kuhnt D, Becker A, Ganslandt O, Bauer M, Buchfelder M, Nimsky C. Correlation of the extent of tumor volume resection and patient survival in surgery of glioblastoma multiforme with high-field intraoperative MRI guidance. Neuro Oncol. 2011;13(12):1339-48. https://doi.org/10.1093/neuonc/ nor 133

34. Sanai N, Polley MY, McDermott MW, Parsa AT, Berger MS. An extent of resection threshold for newly diagnosed glioblastomas. J Neurosurg. 2011;115(1):3-8. https://doi.org/10.3171/2011.2.JNS10998

35. Sarbu N, Oleaga L, Valduvieco I, Pujol T, Berenguer J. Increased signal intensity in flair sequences in the resection cavity can predict progression and progression-free survival in gliomas. Neurocir. 2016;27:269-76. https://doi.org/10.1016/j.neucir.2016.04.002

36. Louis DN, Ohgaki H, Wiestler OD, Cavenee WK, Burger PC, Jouvet A, et al. The 2007 WHO classification of tumours of the central nervous system. Acta Neuropathol. 2007;114(2):97-109. https:// doi.org/10.1007/s00401-007-0243-4

37. Stupp R, Taillibert S, Kanner AA, Read W, Steinberg DM, Lhermitte B, et al. Effect of tumor-treating fields plus maintenance temozolamide vs maintenance temozolamide alone on survival in patients with glioblastoma: a randomized clinical trial. JAMA. 2017;318(23):2306-16. https://doi. org/10.1001/jama.2017.18718 
38. Wick W, Gorlia T, Bendszus M, Taphoorn M, Sahm F, Harting I, et al. Lomustine and bevacizumab in progressive glioblastoma. N Engl J Med. 2017;377(20):1954-63. https://doi.org/10.1056/ NEJMoal 707358

39. Kleinschmidt-Demasters BK, Aisner DL, Birks DK, Foreman NK. Epithelioid GBMs show a high percentage of BRAF V600E mutation. Am J Surg Pathol. 2013;37(5):685-98. https://doi.org/10.1097/ PAS.0b013e31827f9c5e

40. Kaley T, Touat M, Subbiah V, Hollebecque A, Rodon J, Lockhart C, et al. BRAF Inhibition in BRAFV600 - mutant gliomas: Results from the VE-Basket Study. J Clin Oncol. 2018;36(35):3477-84. https://doi.org/10.1200/JCO.2018.78.9990

41. Weller M, Stupp R, Hegi ME, van den Bent M, Tonn JC, Sanson M, et al. Personalized care in neurooncology coming of age: why we need MGMT and 1p/19q testing for malignant glioma patients in clinical practice. Neuro Oncol. 2012;14(SUPPL.4):100-8. https://doi.org/10.1093/neuonc/nos206

42. Tang X, Xu P, Wang B, Luo J, Fu R, Huang K, et al. Identification of a specific gene module for predicting prognosis in glioblastoma patients. Front Oncol. 2019;9(AUG):1-11. https://doi.org/10.3389/ fonc. 2019.00812

43. Cerami E, Demir E, Schultz N, Taylor BS, Sander C. Automated network analysis identifies core pathways in glioblastoma. PLoS One. 2010;5(2). https://doi.org/10.1371/journal.pone.0008918

44. Le Rhun E, Preusser M, Roth P, Reardon DA, van den Bent M, Wen P, et al. Molecular targeted therapy of glioblastoma. Cancer Treat Rev. 2019 Set;80:101896. https://doi.org/10.1016/j.ctrv.2019.101896

45. Zhang J, Zhang S, Wang Y, Zhang XS. Identification of mutated core cancer modules by integrating somatic mutation, copy number variation, and gene expression data. BMC Syst Biol. 2013;7(Suppl 2):54. https://doi.org/10.1186/1752-0509-7-S2-S4

46. McLendon R, Friedman A, Bigner D, Van Meir EG, Brat DJ, Mastrogianakis GM, et al. Comprehensive genomic characterization defines human glioblastoma genes and core pathways. Nature. 2008;455(7216):1061-8. https://doi.org/10.1038/nature07385

47. Gu Y, Wang H, Qin Y, Zhang Y, Zhao W, Qi L, et al. Network analysis of genomic alteration profiles reveals co-altered functional modules and driver genes for glioblastoma. Mol Biosyst. 2013;9(3): 467-77. https://doi.org/10.1039/c2mb25528f

48. Tang C, Makusheva Y, Sun H, Han W, Iwakura Y. Myeloid C-type lectin receptors in skin/mucoepithelial diseases and tumors. J Leukoc Biol. 2019;106(4):903-17. https://doi.org/10.1002/JLB.2RI0119-031R

49. Xu P, Yang J, Liu J, Yang X, Liao J, Yuan F, et al. Identification of glioblastoma gene prognosis modules based on weighted gene co-expression network analysis 06 Biological Sciences 0604 Genetics. BMC Med Genomics. 2018;11(1):1-12. https://doi.org/10.1186/s12920-018-0407-1

50. Yokogami K, Yamasaki K, Matsumoto F, Yamashita S, Saito K, Tacheva A, et al. Impact of PCRbased molecular analysis in daily diagnosis for the patient with gliomas. Brain Tumor Pathol. 2018;35(3):141-7. https://doi.org/10.1007/s10014-018-0322-3

51. Shi ZF, Aibaidula A, Tang QS, Shen YW, Chen H, Wu JS, et al. Methods of glioma sample processing for molecular diagnosis for the glioma tissue bank project. Biopreserv Biobank. 2015;13(1):31-6. https://doi.org/10.1089/bio.2014.0089

52. Eder K, Kalman B. Molecular Heterogeneity of Glioblastoma and its Clinical Relevance. Pathol Oncol Res. 2014;20(4):777-87. https://doi.org/10.1007/s12253-014-9833-3

53. Jacob F, Salinas RD, Zhang DY, Nguyen PTT, Schnoll JG, Wong SZH, et al. A Patient-Derived Glioblastoma Organoid Model and Biobank Recapitulates Inter- and Intra-tumoral Heterogeneity. Cell. 2020;180(1):188-204.e22. https://doi.org/10.1016/j.cell.2019.11.036 
